\title{
BMJ Open An observational study of retail availability and in-store marketing of e-cigarettes in London: potential to undermine recent tobacco control gains?
}

\author{
Robert Hsu, ${ }^{1,2}$ Allison E Myers, ${ }^{3}$ Kurt M Ribisl, ${ }^{3,4}$ Theresa M Marteau ${ }^{2}$
}

To cite: Hsu R, Myers AE, Ribisl KM, et al. An observational study of retail availability and in-store marketing of e-cigarettes in London: potential to undermine recent tobacco control gains?. BMJ Open 2013;3:e004085.

doi:10.1136/bmjopen-2013004085

- Prepublication history for this paper is available online. To view these files please visit the journal online (http://dx.doi.org/10.1136/ bmjopen-2013-004085).

Received 20 September 2013 Revised 25 October 2013 Accepted 1 November 2013

CrossMark

For numbered affiliations see end of article.

Correspondence to Professor Theresa M Marteau; tm388@cam.ac.uk

\section{ABSTRACT}

Objectives: E-cigarette companies and vendors claim the potential of e-cigarettes to help smokers reduce or quit tobacco use. E-cigarettes also have the potential to renormalise smoking. The purpose of this study was to describe the availability and in-store marketing of ecigarettes in London, UK stores selling tobacco and alcohol.

Design: Observational study.

Setting: Small and large stores selling alcohol and tobacco in London, UK.

Primary and secondary outcome measures: The number of stores selling e-cigarettes, the number of stores with an interior or exterior e-cigarette advertisement, the number of stores with an e-cigarette point-of-sale movable display, store size, deprivation index score for store's corresponding lower super output area.

Results: Audits were completed in 108 of 128 selected stores. 62 of the audited stores $(57 \%)$ sold e-cigarettes. E-cigarette availability was unrelated to store size. There was a statistically non-significant trend towards increased availability in more deprived areas $(p=0.069)$. 31 of the 62 stores $(50 \%)$ selling e-cigarettes had a point-of-sale movable display, with all but one found in small stores. Two small stores had interior advertisements and eight had exterior advertisements. No advertisements were observed in large stores.

Conclusions: This audit revealed widespread availability of e-cigarettes and in-store marketing in London, UK. Even if e-cigarettes prove to be an effective cessation aid, their sale and use are resulting in an increasing public presence of cigarette-like images and smoking behaviour. After decades of work to denormalise smoking, these findings raise the question of whether e-cigarettes are renormalising smoking.

\section{INTRODUCTION}

Although consumption of conventional cigarettes has decreased in the USA and the $\mathrm{UK}^{1}{ }^{2}$

\section{Strengths and limitations of this study}

- This is the first empirical study to describe the availability and in-store marketing of e-cigarettes in the UK.

- We used standard methods to improve accuracy by physically enumerating tobacco and alcohol retailers in the field (since there is no tobacco licensing in England) and by using a mobile data collection system.

- We may have underestimated the true availability of e-cigarettes as we sampled only stores selling both alcohol and tobacco.

- The low statistical power of this study makes it difficult to reliably assess the association between e-cigarette availability and area of deprivation.

in recent years, awareness and use of electronic cigarettes (referred to as e-cigarettes in this paper) have increased greatly in the past few years in the USA and the $\mathrm{UK}^{3}{ }^{4}$ E-cigarettes are cigarette-shaped devices that heat a solution of tobacco-derived nicotine and other chemicals to form a vapour that is inhaled by the user. Existing studies on e-cigarette users show that a majority of them try e-cigarettes as a way to quit smoking, reduce smoking or satisfy smoking urges in places where smoking is prohibited. ${ }^{4-6}$ These trends in e-cigarette use and the rise of e-cigarettes have drawn a mixed ${ }^{7}{ }^{8}$ but generally a positive reaction ${ }^{9-12}$ from the public health community, based on the belief that e-cigarettes might be less harmful than combusted tobacco products and may potentially aid cessation. A recent longitudinal study showed that smokers had similar abstinence rates using e-cigarettes and nicotine patches for quitting ${ }^{13}$; however, another longitudinal study examining variation in quit success 
between e-cigarette users and non-users showed no differences, which supports e-cigarettes as a potential facilitator for dual use. ${ }^{5}$ The US Food and Drug Administration (FDA) has expressed concerns over e-cigarettes' safety and effectiveness as cessation devices ${ }^{14}$ and has stated a desire to assert jurisdiction over currently non-regulated tobacco products by October 2013. ${ }^{15}$ In the summer of 2013, the UK Medicines and Healthcare Products Regulatory Agency (MHRA) released its decision to regulate e-cigarettes as medicines in 2016. ${ }^{16}$ Yet little is known about the social and behavioural consequences of e-cigarette availability and marketing. These pervasive new cues that potentially promote tobacco use are important in a country like the UK, which has successfully banned point-of-sale tobacco advertising in small and large stores, as well as tobacco displays in large stores, with large stores defined as those greater than $280 \mathrm{~m}^{2} .{ }^{17}$ In this article, we present findings of the first store audit of e-cigarettes in the UK. Our primary aim was to describe the availability of e-cigarettes and their promotion in stores. Our secondary aim was to describe the associations between e-cigarette availability and neighbourhood deprivation.

\section{METHODS}

\section{Setting}

The data presented here were collected as a part of an observational point-of-sale audit of the sales and marketing of tobacco products and alcoholic beverages in London, UK stores selling both products. Data collection took place over 3 weeks in June and July 2013.

\section{Sampling}

Multistage area-based sampling was used. First, 18 middle super output areas (MSOAs) were selected with the probability of selection proportionate to population size. These MSOAs were composed of multiple lower super output areas (LSOAs), which are a collection of geographic areas of similar populations and social homogeneity created from clusters of adjacent postcodes. ${ }^{18} 19$ Given that England lacks tobacco retailer licensing, we walked each street of each output area by foot to generate a list of all retailers selling both tobacco and alcohol. In total, 128 stores, 116 small and 12 large, were identified through this process.

\section{Data collection}

Data collectors conducted store audits using web-based software on a 3G-cellular-enabled Apple iPad Mini. Audits took place primarily between 9:00 and 19:00. On entering a store, the data collector introduced himself or herself (RH or AEM) and briefly explained the study to a clerk or manager in the store.

\section{Measures}

Availability and promotion

Our audit tool included dichotomous measures for whether stores sold e-cigarettes, promoted them with

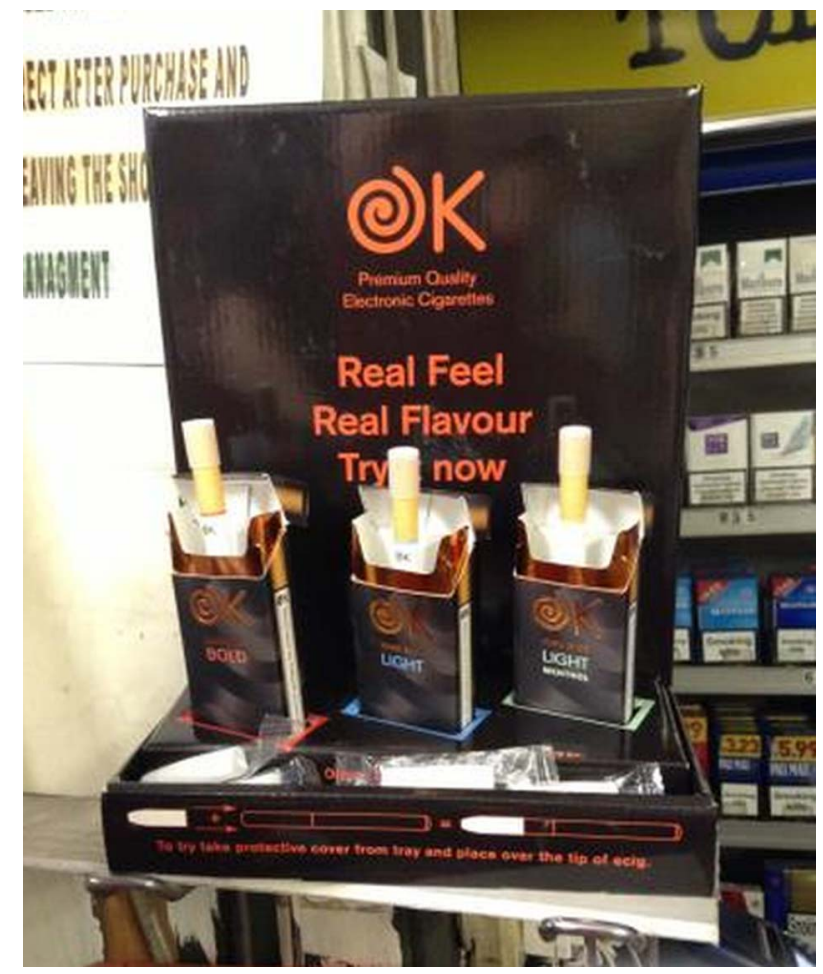

Figure 1 Point-of-sale movable display that invites store customers to sample the e-cigarette by providing disposable plastic covers to put over the tip.

interior or exterior advertisements, or featured a movable display. Point-of-sale movable displays are branded structures that combine advertising with product presentation. They are commonly found at the cash register and are made of plastic or cardboard. See figure 1 for an example of a point-of-sale movable display and figure 2 for an advertisement.

\section{Neighbourhood deprivation}

We used store postcodes to identify the corresponding LSOA deprivation index score based on the 2010 English Indices of Multiple Deprivation, ${ }^{20}$ with higher scores indicating higher levels of deprivation. We divided our data based on the quartiles for the entire set of deprivation scores.

\section{Size}

We classified stores into two categories: small $\left(<280 \mathrm{~m}^{2}\right)$ and large $\left(\geq 280 \mathrm{~m}^{2}\right)$. We were interested in differences in e-cigarette availability and marketing possibly resulting from the tobacco display ban in large stores. E-cigarettes, which are not considered tobacco products in the UK, could be an attractive product to large stores by allowing them to continue drawing revenue from smokers since their display and marketing are not restricted. Stores of an ambiguous size were measured using a laser-measuring device. 


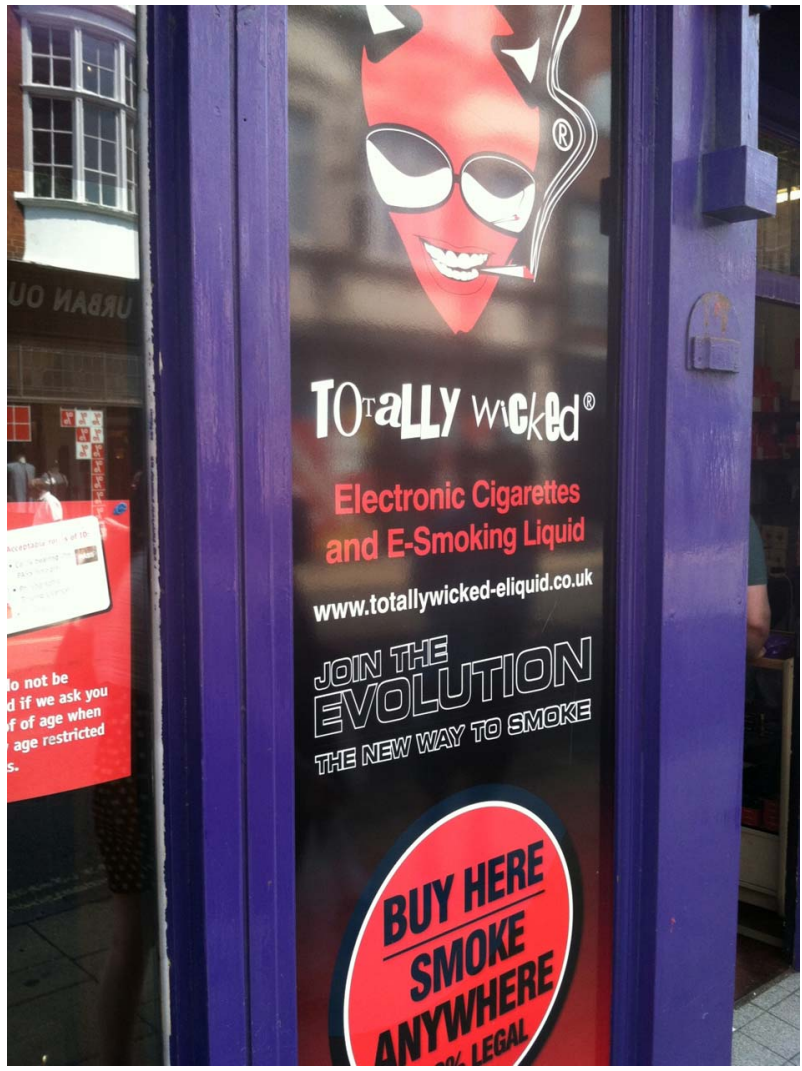

Figure 2 An example of an exterior e-cigarette advertisement.

\section{Data analysis}

Descriptive statistics were computed to characterise e-cigarette availability and promotion. $\chi^{2}$ Tests were used to examine associations between the following: neighbourhood deprivation and e-cigarette availability; store size and e-cigarette availability; store size and the presence of point-of-sale movable displays and store size and the presence of advertisements. Data analyses were performed in SPSS (V.21.0, IBM Corp, Armonk, New York, USA).

\section{RESULTS}

\section{Description of sample}

A map of the sampled areas is shown in figure 3. We attempted audits in each of the 128 identified stores, of which 108 audits were completed (96 small and 12 large). Twenty audits were incomplete due to store refusals $(n=18)$ or stores being closed $(n=2)$, giving an $84 \%$ $(108 / 128)$ completion rate. The audited stores spanned areas of low and high deprivation (4.43-64.32; mean 28.70 (SD 12.30)) but on average were in areas of higher deprivation than for England as a whole (mean 21.67 (SD 12.35)). (Two stores were excluded from this analysis because their postcodes did not yield corresponding LSOA deprivation index scores.) Ten of the 12 large stores were part of chains (eg, Tesco and Sainsbury's), while nearly all of the small stores appeared to be independently owned.

\section{E-cigarette availability}

Overall, 62 of the 108 stores sold e-cigarettes (57\%): 53 of the 96 small stores (55\%) and 9 of the 12 large stores $(75 \%)$. The distribution of e-cigarette sales in small and large stores was not significantly different $\left(\chi^{2} 2.490\right.$, $\mathrm{df}=1, \mathrm{p}=0.115)$. There was a statistically non-significant trend towards stores located in higher quartiles of deprivation to be selling e-cigarettes, with $46.9 \%$ of stores in the most deprived quartile selling e-cigarettes, compared with $37.5 \%$ of stores in the least-deprived quartile $\left(\chi^{2} 7.103, \mathrm{df}=3, \mathrm{p}=0.069\right)$.

\section{E-cigarette promotion}

Thirty-one of the 62 stores selling e-cigarettes had a point-of-sale movable display $(50 \%)$ with all but 1 of these being in small stores. Small stores were more likely to have a point-of-sale movable display $\left(\chi^{2} 6.369, \mathrm{df}=1\right.$, $\mathrm{p}=0.012)$ than were large stores. Two stores had an interior advertisement $(2 \%(2 / 62))$ and eight stores had an exterior advertisement $(15 \%(8 / 62))$, with none of these being in large stores. However, there was no significant difference between small and large stores in the presence of advertisements $\left(\chi^{2} 1.560, \mathrm{df}=1, \mathrm{p}=0.212\right)$.

\section{DISCUSSION}

\section{Summary of key findings}

Our results show a high availability of e-cigarettes in small and large stores, with an overall availability of $57 \%$ (95\% CI $48 \%$ to $67 \%$ ) in our study sample. This is significantly higher than the $34 \%$ rate we found in an unpublished 2012 national study conducted in the USA, in the only other audit of e-cigarette availability. Given the recent increased investment in e-cigarettes by the tobacco industry, ${ }^{21}{ }^{22}$ continued growth in e-cigarette availability is to be expected. Small stores had a noteworthy amount of e-cigarette marketing materials in the form of point-of-sale movable displays but not advertisements. Many of these point-of-sale movable displays engaged consumers directly by inviting them to try the product (see figure 1). We also noticed after beginning data collection that some small and large stores had e-cigarette brochures available at the point-of-sale, which can be included as a measure of the presence of marketing materials in future studies. In contrast to the USA study, which found that e-cigarettes were more prevalent in areas with higher household incomes, we found a statistically non-significant trend towards higher availability in more deprived neighbourhoods. Given that existing studies on e-cigarette user profiles show that most are existing or former cigarette smokers, ${ }^{4}{ }^{23}$ we speculate that this trend reflects the higher rate of smoking in more deprived areas. ${ }^{24}$ Furthermore, the costeffectiveness of e-cigarettes compared to conventional cigarettes, as emphasised in observed marketing materials, could make them more attractive to smokers in more deprived areas. 
Strengths and limitations of the current study

Our study has two key strengths. First, it is the first empirical study on e-cigarette availability and promotion in the UK. Second, given the field context of our study, we used standard methods to achieve accurate data collection, including physically enumerating tobacco and alcohol retailers and using a mobile data collection system on a tablet device, a recent trend in point-of-sale audits. ${ }^{25-27}$ Potential advantages of a mobile data collection system include reducing data entry errors, having a single device for data collection that includes taking photographs and making the data collector less conspicuous than she/he would be using a clipboard given the ubiquity of tablet devices.

The limitations of the study can be attributed to the nature of our sampling. With low statistical power, especially in large stores, it is difficult to come to a firm conclusion about the association between e-cigarette availability and neighbourhood deprivation, as well as differences in the availability and marketing of e-cigarettes in small and large stores. We only sampled an urban area and audited retailers selling both tobacco and alcohol, so our results cannot be generalised to the UK and for all types of retailers. Although the MSOAs of our audited stores were not completely representative of England, they were diverse, varying in population density, ethnicity and household number.

\section{IMPLICATIONS AND CONCLUSIONS}

A larger study is needed to estimate more precisely the availability of e-cigarettes and their marketing in the UK and elsewhere. This could also elucidate the association between neighbourhood deprivation and e-cigarette availability. Furthermore, more detailed aspects of e-cigarette marketing, such as pricing, advertisement size, message appeals, imagery and brands can be collected. Mindful of the limitations in the current study, the results nonetheless raise concerns about the scale of e-cigarette sales and in-store marketing. Assessing the full range of benefits and harms of rising e-cigarette use requires consideration of a wider range of the increasing presence and marketing of e-cigarettes in order to ascertain the impact on non-users (including tobacco smokers, tobacco smokers trying to quit, non-smokers and youth), as well as e-cigarette users. Prior studies show that smoking paraphernalia ${ }^{28}$ and point-of-sale marketing can cue cravings, ${ }^{29}$ increasing the difficulty for smokers to quit or causing former smokers to relapse. It is therefore possible that e-cigarette use and its marketing could cue tobacco smoking in current or former smokers given that the appearance of e-cigarettes and associated behaviours are remarkably similar to those of cigarettes. The desire for e-cigarette users to use e-cigarettes to satisfy nicotine cravings in smoking-restricted areas ${ }^{4-6}$ could also have negative behavioural effects on youth and non-smokers by normalising smoking-related behaviours. Whether e-cigarettes are a gateway to smoking initiation is unknown and remains a possibility. If e-cigarettes are truly more available in more deprived areas, as suggested by our data, smoking disparities between the wealthy and the poor may only persist with the increasing popularity of e-cigarettes, reversing progress towards narrowing the gap. Apart from the concerns we have raised, others have commented on the potential for dual use ${ }^{7}$ and e-cigarette product safety, standardisation and quality. ${ }^{78}$
Figure 3 Map of the sampled areas in London, MSOAs, middle super output areas.

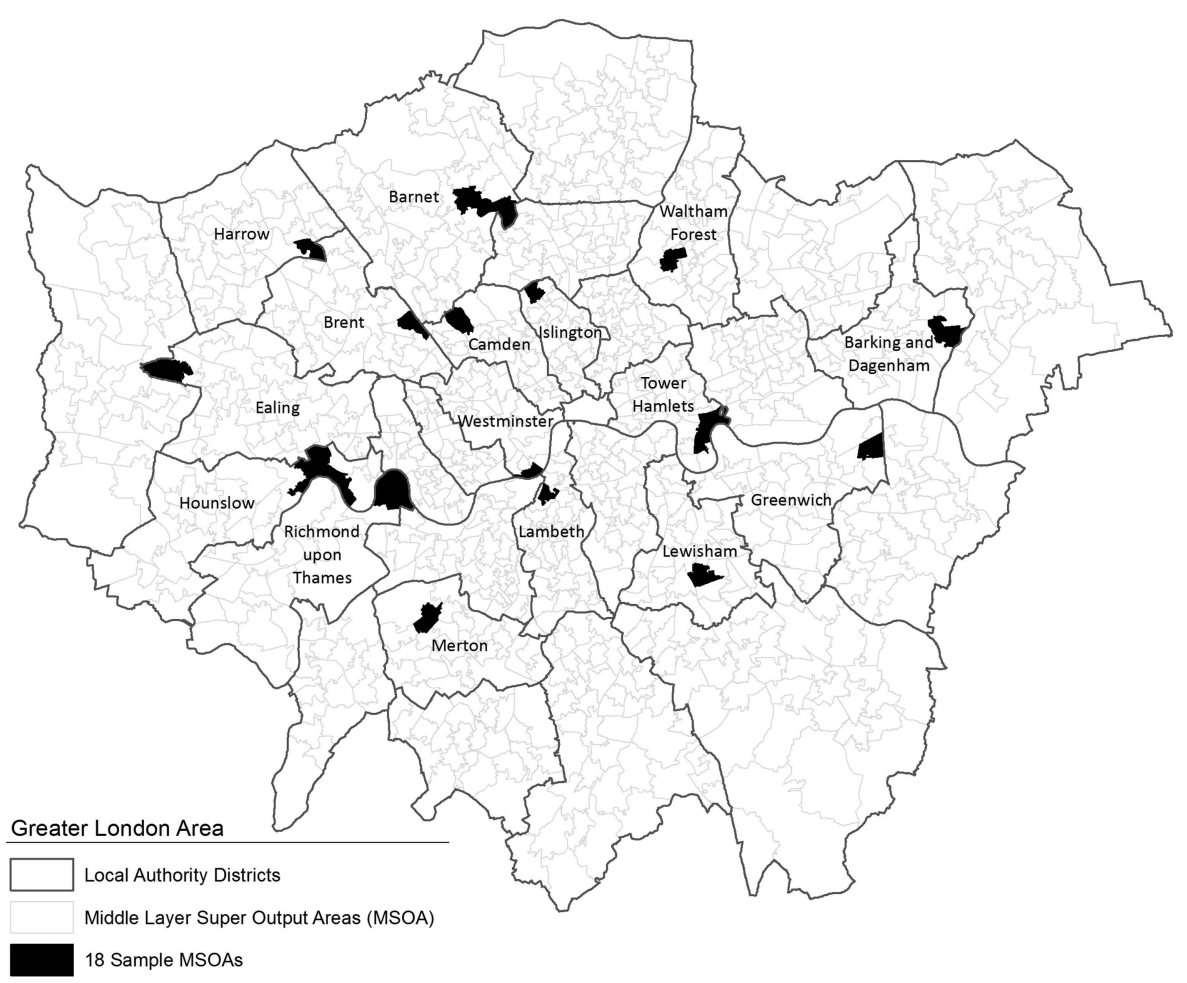


In summary, even if e-cigarettes are proven to provide a safe delivery mechanism for nicotine and are an effective cessation aid, their sale and use have resulted in a renewed and increasing public presence of cigarette-like objects, images and smoking behaviour. After decades of work to denormalise smoking, the question of whether e-cigarettes are renormalising smoking merits urgent empirical study.

\section{Author affiliations}

${ }^{1}$ College of Arts \& Sciences and The Wharton School, University of Pennsylvania, Philadelphia, Pennsylvania, USA

${ }^{2}$ Behaviour and Health Research Unit, University of Cambridge, Institute of Public Health, Cambridge, UK

${ }^{3}$ Department of Health Behavior, Gillings School of Global Public Health, University of North Carolina at Chapel Hill, Chapel Hill, North Carolina, USA ${ }^{4}$ Lineberger Comprehensive Cancer Center, School of Medicine, University of North Carolina at Chapel Hill, Chapel Hill, North Carolina, USA

Acknowledgements The authors would like to thank Milica Vasiljevic, PhD, and Rachel Pechey, PhD, for their valuable comments on the manuscript, Chris Lowry and Katy Scammell of ASH for their assistance with data collection, and Lisa Isgett for preparation of the map shown in figure 3.

Contributors AEM, KMR and TMM designed the study. AEM and KMR provided the data collection software. AEM and $\mathrm{RH}$ collected data, and $\mathrm{RH}$ conducted data analysis. TMM had the idea for the paper. $\mathrm{RH}$ drafted the paper, with AEM, KMR and TMM contributing to subsequent drafts. All authors approved the final manuscript. TMM is the guarantor.

Funding This study was funded by a joint grant from the University of Cambridge, England and the University of North Carolina at Chapel Hill's Gillings School of Global Public Health, USA. The Behaviour and Health Research Unit (BHRU) is part funded by the UK Department of Health Policy Research Programme as the Policy Research Unit in Behaviour and Health (PR-UN-0409-10109). This study was conducted independently of the funders, and the views expressed in this paper are those of the authors and not necessarily those of the funders.

Competing interests KMR and AEM have developed the Counter Tobacco Store Audit Center data collection system used in this study and a Store Mapper tobacco retailer mapping system (not used in this study). Both will generate royalties when licensed. KMR and AEM receive compensation as the Executive Director and Deputy Director, respectively, of Counter Tools, a non-profit organisation with the mission to disseminate the Store Audit Center and the Store Mapper, and associated training and technical assistance to communities addressing point of sale tobacco control issues. $\mathrm{RH}$ was funded as a summer intern through the Roy and Diana Vagelos Life Sciences \& Management Program and the Elliman Internship Fund.

Provenance and peer review Not commissioned; externally peer reviewed.

Data sharing statement No additional data are available.

Open Access This is an Open Access article distributed in accordance with the Creative Commons Attribution Non Commercial (CC BY-NC 3.0) license, which permits others to distribute, remix, adapt, build upon this work noncommercially, and license their derivative works on different terms, provided the original work is properly cited and the use is non-commercial. See: http:// creativecommons.org/licenses/by-nc/3.0/

\section{REFERENCES}

1. Tynan MA, McAfee T, Promoff G, et al. Consumption of cigarettes and combustible tobacco-United States, 2000-2011. Centers for Disease Control and Prevention, Report number: 30, 2012.
2. Smoking statistics: who smokes and how much (Fact Sheet). Action on Smoking and Health (ASH). 2013. http://ash.org.uk/files/ documents/ASH_106.pdf. (accessed 18 Dec 2013).

3. King BA, Alam S, Promoff G, et al. Awareness and ever use of electronic cigarettes among U.S. adults, 2010-2011. Nicotine Tob Res 2013;15:1623-7.

4. Dockrell M, Morison R, Bauld L, et al. E-cigarettes: prevalence and attitudes in Great Britain. Nicotine Tob Res 2013;15:1737-44.

5. Adkison SE, O'Connor RJ, Bansal-Travers M, et al. Electronic nicotine delivery systems: international tobacco control four-country survey. Am J Prev Med 2013;44:207-15.

6. Kralikova E, Novak J, West O, et al. Do e-cigarette have the potential to compete with conventional cigarettes? A survey of conventional cigarette smokers' experiences with e-cigarettes. Chest 2013;144:1609-14.

7. Chapman S. Should electronic cigarettes be as freely available as tobacco? No. BMJ 2013;346:f3840.

8. Flouris $A D$, Oikonomou $D N$. Electronic cigarettes: miracle or menace. BMJ 2010;340:c311.

9. Etter JF. Should electronic cigarettes be as freely available as tobacco? Yes. BMJ 2013;346:f3845.

10. Polosa R, Morjaria JB, Caponnetto $\mathrm{P}$, et al. Effectiveness and tolerability of electronic cigarette in real-life: a 24-month prospective observational study. Intern Emerg Med 2013:1-10. Epub 2013/07/23.

11. Hajek P. Commentary on Wagener et al. (2012): e-cigarettes: a vulnerable promise. Addiction 2012;107:1549.

12. Wagener TL, Siegel M, Borrelli B. Electronic cigarettes: achieving a balanced perspective. Addiction 2012;107:1545-8.

13. Bullen C, Howe C, Laugesen M. Electronic cigarettes for smoking cessation: a randomized controlled trial. Lancet 2013;382:1629-37.

14. Chen I-L. FDA summary of adverse events on electronic cigarettes. Nicotine Tob Res 2013;15:615-16.

15. Office of Information and Regulatory Affairs. Tobacco products subject to the Federal Food, Drug, and Cosmetic Act, as amended by the Family Smoking Prevention and Tobacco Control Act. [Online] http://www.reginfo.gov/public/do/eAgendaViewRule?publd=201304\& $\mathrm{RIN}=0910-A G 38$ (accessed 20 Aug 2013).

16. Medicines and Healthcare Products Regulatory Agency. UK moves towards safe and effective electronic cigarettes and other nicotine-containing products. [Press release] 12 June 2013.

17. Action on Smoking and Health (ASH) Briefing: Tobacco Displays at the Point of Sale. 2012. http://ash.org.uk/files/documents/ASH_701. pdf. (accessed 18 Dec 2013).

18. Office for National Statistics. Output areas (OA). [Online] http://www. ons.gov.uk/ons/guide-method/geography/beginner-s-guide/census/ output-area--oas-/index.html (accessed 6 Aug 2013).

19. Office for National Statistics. Super output areas explained. [Online] http://neighbourhood.statistics.gov.uk/HTMLDocs/nessgeography/ superoutputareasexplained/output-areas-explained.htm (accessed 21 Aug 2013).

20. United Kingdom Government. English indices of deprivation. 2010. https://www.gov.uk/government/publications/english-indices-ofdeprivation-2010 (accessed 9 Aug 2010).

21. Kamerow D. Big tobacco lights up e-cigarettes. BMJ 2013;346:f3418

22. Hirschler B. Factbox: big tobacco companies bet on e-cigarettes. Reuters, 2013. http://uk.reuters.com/article/2013/06/13/us-ecigarettesfactbox-idUSBRE95COFG20130613 (accessed 10 Aug 2013).

23. Etter JF, Bullen C. Electronic cigarette: users profile, utilization, satisfaction and perceived efficacy. Addiction 2011;106:2017-28.

24. Shohaimi S, Luben R, Wareham N, et al. Residential area deprivation predicts smoking habit independent of individual educational level and occupational social class. A cross sectional study in the Norfolk cohort of the European Investigation into Cancer (EPIC-Norfolk). J Epidemiol Commun H 2003;57:270-6.

25. Salloum RG, Nakkash RT, Myers AE, et al. Point-of-sale tobacco advertising in Beirut, Lebanon following a national advertising ban. BMC Public Health 2013;13:534.

26. Rose SW, Myers AE, D'Angelo $\mathrm{H}$, et al. Retailer Adherence to Family Smoking Prevention and Tobacco Control Act, North Carolina, 2011. Prev Chronic Dis 2013;10:120184.

27. Cantrell J, Kreslake JM, Ganz O, et al. Marketing little cigars and cigarillos: advertising, price, and associations with neighborhood demographics. Am J Public Health 2013;103:1902-9.

28. Carter BL, Tiffany ST. Meta-analysis of cue-reactivity in addiction research. Addiction 1999;94:327-40.

29. Paynter J, Edwards R. The impact of tobacco promotion at the point of sale: a systematic review. Nicotine Tob Res 2009;11:25-35. 